\section{Investigations on the Rare Earth Terpyridyl System}

\author{
II. Preliminary Observations on the Luminescence \\ of $\mathrm{Eu}^{3^{+}}$and $\mathrm{Tb}^{3+}$ Terpyridyl Complexes * \\ Shyama P. Sinha \\ Cyanamid European Research Institute \\ Cologny, Geneva, Switzerland \\ (Z. Naturforschg. 20 a, $164-165$ [1965] ; eingeg. am 27. Dézember 1964)
}

Recently the organic complexes of trivalent rare earths have attracted considerable attention as possible laser materials, where optical pumping can be conveniently carried out resulting in a relatively high fluorescence yield ${ }^{1-19}$. All of these studies involved complexes having oxygens as coordinating atoms. In our search for ligands containing atoms other than oxygens and preferably nitrogens as coordination centers we have previously shown ${ }^{20}$ the intramolecular energy transfer from $2,2^{\prime}$-dipyridyl molecules to the coordinated $\mathrm{Sm}^{3^{+}}, \mathrm{Eu}^{3^{+}}, \mathrm{Tb}^{3^{+}}$and $\mathrm{Dy}^{3^{+}}$to give rise to line fluorescence characteristics of these coordinated metal ions. Similar fluorescence was observed in the rare-earth-phenanthroline system ${ }^{21}$.

It was of interest to investigate the analogous $2,2^{\prime}, 2^{\prime \prime}$. terpyridyl complexes and in this report preliminary observations on the fluorescence characteristics of $\mathrm{Eu}^{3^{+}}$ and $\mathrm{Tb}^{3+}$ terpyridyl complexes are presented. The absorption spectra of the methanolic solutions of monoterpyridyl complexes of lighter lanthanides are described elsewhere ${ }^{22}$ and those of heavier lanthanides will be reported soon.

\section{Fluorescence of the Solid Chelates}

By exciting the terpyridyl chelates of $\mathrm{Eu}^{3^{+}}$and $\mathrm{Tb}^{3^{+}}$ with long-wave ultraviolet light, the characteristic emissions of the coordinated ions are observed and the data are presented in Table 1 . Undoubtedly the fluorescence

* Presented at the Conference on Luminescence of Solids, University of Hull, England, September 1964.

1 S. I. Weissman, J. Chem. Phys. 10, 214 [1942].

2 S. I. Weissman, J. Chem. Phys. 18, 1258 [1950].

${ }^{3}$ G. A. Crosby, R. E. Whan, and R. M. Aline, J. Chem. Phys. 34, 743 [1961].

4 R.E. Whan and G. A. Crosby, J. Mol. Spectr. 8, 315 [1962].

5 G.A. Crosby, R.E. Whan, and J.J.Freeman, J. Phys. Chem. 66, 2493 [1962].

6 E. NArdi and S. YAtsiv, J. Chem. Phys. 37, 2333 [1962].

7 E. J. Schimitscher and E. G. K. Schwartz, Nature, Lond. 196, 832 [1962].

8 J. J. Freeman and G. A. Crosby, J. Phys. Chem. 67, 2717 [1963].

9 M. L. Bhaumik, H. Lyons, and P. C. Fletcher, J. Chem. Phys. 38, 568 [1963].

10 H. Winston, O. J. Marsh, C. K. Suzuki, and C. L. Telk, J. Chem. Phys. 39, 267 [1963].

11 H. Samelson and A. Lempicki, J. Chem. Phys. 39, 110 [1963].

12 A. Lempicki and H. Samelson, Phys. Letters 4, 133 [1963].

13 N. E. Wolf and R. J. Pressley, Appl. Phys. Letters 2, 152 [1963].

14 E. J. Sснімітsснек, Appl. Phys. Letters 3, 117 [1963]. of these chelates resulted due to the intramolecular transfer of the absorbed energy by the ligand to the central metal ions. According to the present concept ${ }^{3-5}$ of intramolecular energy transfer mechanism, the energy absorbed in the singlet state of the ligand crosses over to the triplet level from where the energy migrates to a low lying $4 \mathrm{f}$-level of the rare earth ion. The transferring level according to Freeman and $\mathrm{C}_{\text {RosBy }}{ }^{8}$ is some higher triplet level than the one from which the phosphorescence originates.

The emission spectra of $\mathrm{Eu}(\mathrm{Terp}) \mathrm{Cl}_{3} \cdot \mathrm{H}_{2} \mathrm{O}$ and $\mathrm{Eu}(\text { Terp })_{2} \mathrm{Cl}_{3} \cdot 4 \cdot \mathrm{H}_{2} \mathrm{O} \quad$ (Terp = terpyridyl molecule) consist of a large number of lines. The transitions ${ }^{5} \mathrm{D}_{0} \rightarrow{ }^{7} \mathrm{~F}_{1}$ and ${ }^{5} \mathrm{D}_{0} \rightarrow{ }^{7} \mathrm{~F}_{2}$ of $\mathrm{Eu}^{3^{+}}$in these chelates show a group of three and a group of four lines respectively ${ }^{23}$. The observed splitting of ${ }^{7} \mathrm{~F}_{1}$ may be compared to the similar splitting in europium naphthalate 20 and that of ${ }^{7} \mathrm{~F}_{2}$ to europium-tris-dibenzoylmethide ${ }^{24}$. A slight shift of these transitions towards higher wavenumbers was noted in the case of europium-bis-terpyridyl chloride chelates. A rough comparison of the ${ }^{5} \mathrm{D}_{0} \rightarrow{ }^{7} \mathrm{~F}_{2}$ transition in europium chelates with neutral nitrogen containing ligands shows a linear relationship of the intensity with the number of coordinated nitrogens. It is also remarkable that the intensity of the ${ }^{5} \mathrm{D}_{0} \rightarrow{ }^{7} \mathrm{~F}_{2}$ transition in the case of dipyridyl and terpyridyl complexes is higher than in the phthalate and naphthalate complexes. It is possible that the energy transfer through a Eu-O ionic bond is less efficient than a covalent europium-ligand bond. We assume that the intensification of ${ }^{5} \mathrm{D}_{0} \rightarrow{ }^{7} \mathrm{~F}_{2}$ transitions in dipyridyl and terpyridyl complexes is possibly due to a slight intermixing ${ }^{25}$ of the triplet state of the ligands with the ${ }^{5} \mathrm{D}_{0}$ and ${ }^{5} \mathrm{D}_{1}$ level of $\mathrm{Eu}^{3^{+}}$.

The strong green fluorescence $\left({ }^{5} \mathrm{D}_{4} \rightarrow{ }^{7} \mathrm{D}_{5}\right)$ transition of $\mathrm{Tb}(\mathrm{Terp})\left(\mathrm{NO}_{3}\right)_{3}$ has also been examined and the transitions originating from the ${ }^{5} \mathrm{D}_{4}$ level of $\mathrm{Tb}^{3+}\left(4 \mathrm{f}^{8}\right)$ and terminating at the ${ }^{7} \mathrm{~F}$ multiplets viz ${ }^{7} \mathrm{~F}_{6},{ }^{7} \mathrm{~F}_{5},{ }^{7} \mathrm{~F}_{4}$, ${ }^{7} \mathrm{~F}_{3}$ and ${ }^{7} \mathrm{~F}_{2}$ have been identified (Table 1).

15 M. L. Bhaumik and C. L. Telk, J. Opt. Soc. Amer. 54, 1211 [1964]

16 E. H. Hufrman, Nature, Lond. 200, 158 [1963].

17 H. Samelson, A. Lempicki, V. A. Brophy, and C. Brecher, J. Chem. Phys. 40, 2547 [1964].

18 H. Samelson, A. Lempicki, and C. Brecher, J. Chem. Phys. 40, 2553 [1964]

19 F. Halverson, J. S. Brinen, and J. R. Leto, J. Chem. Phys. 40, 2790 [1964] ; 41, 157 [1964]

20 S. P. Sinha, C. K. Jørgensen, and R. Pappalardo, Z. Naturforschg. 19 a, 434 [1964] .

21 L. I. Kononenko, R. S. Lauer, and N. S. Poluektov, Zh. Analit. Khim. 18, 1468 [1963] ; Chem. Abstr. 60, 11366 [1964].

22 S. P. SinHa, Part I, Forthcoming paper.

23 The width of ${ }^{7} \mathrm{~F}_{2}$ in the mono and bis terpyridyl chelates is approximately $240 \pm 10 \mathrm{~cm}^{-1}$, and that of bis dipyridyl and naphthalate is 150 and $180 \mathrm{~cm}^{-1}$ respectively.

24 A. Lempicki and H. Samelson, Appl. Phys. Letters 2, 159 [1963].

25 N. McAvoy, N. Filipescu, M. R. Kagan, and F. A. Serafin, J. Phys. Chem. Solids 25, 461 [1964]. 


\begin{tabular}{|c|c|c|}
\hline Chelates & $\begin{array}{c}\text { Observed fluorescence } \\
\text { line }\end{array}$ & Assignments \\
(wavenumber in cm ${ }^{-1}$ ) & \\
\hline Eu (Terp) $\mathrm{Cl}_{3} \cdot \mathrm{H}_{2} \mathrm{O}$ & 16835 & ${ }^{5} \mathrm{D}_{0} \rightarrow{ }^{7} \mathrm{~F}_{1}$ \\
& 16181 & ${ }^{5} \mathrm{D}_{0} \rightarrow{ }^{7} \mathrm{~F}_{2}$ \\
& $16129(\mathrm{Sh})$ & ${ }^{5} \mathrm{D}_{0} \rightarrow{ }^{7} \mathrm{~F}_{3}$ \\
$\mathrm{Eu}\left(\right.$ Terp) ${ }_{2} \mathrm{Cl}_{3} \cdot 4 \mathrm{H}_{2} \mathrm{O}$ & $15380^{\mathrm{a}}$ & ${ }^{5} \mathrm{D}_{0} \rightarrow{ }^{7} \mathrm{~F}_{4}$ \\
& $14390^{\mathrm{a}}$ & ${ }^{5} \mathrm{D}_{0} \rightarrow{ }^{7} \mathrm{~F}_{1}$ \\
& $16892^{7}$ & ${ }^{5} \mathrm{D}_{0} \rightarrow{ }^{7} \mathrm{~F}_{2}$ \\
$\mathrm{~Tb}$ (Terp) $\left(\mathrm{NO}_{3}\right)_{3}$ & $15380^{\mathrm{a}}$ & ${ }^{5} \mathrm{D}_{0} \rightarrow{ }^{7} \mathrm{~F}_{3}$ \\
& $\sim 14390^{\mathrm{a}}$ & ${ }^{5} \mathrm{D}_{0} \rightarrow{ }^{7} \mathrm{~F}_{4}$ \\
& 20284 & ${ }^{5} \mathrm{D}_{4} \rightarrow{ }^{7} \mathrm{~F}_{6}$ \\
& $18349^{5}$ & ${ }^{5} \mathrm{D}_{4} \rightarrow{ }^{7} \mathrm{~F}_{5}$ \\
& $16949^{\mathrm{a}}$ & ${ }^{5} \mathrm{D}_{4} \rightarrow{ }^{7} \mathrm{~F}_{4}$ \\
& $\sim 16000^{\mathrm{a}}$ & ${ }^{5} \mathrm{D}_{4} \rightarrow{ }^{7} \mathrm{~F}_{3}$ \\
& $\sim 15380^{\mathrm{a}}$ & ${ }^{5} \mathrm{D}_{4} \rightarrow{ }^{7} \mathrm{~F}_{2}$ \\
\hline
\end{tabular}

a These lines are observed through a hand spectroscope and are accurate within 100 wavenumbers.

Table 1. Details of fluorescence emission of $\mathrm{Eu}^{3^{+}}$and $\mathrm{Tb}^{3^{+}}$ terpyridyl complexes in the solid state at room temperature.

\section{Fluorescence of Methanolic Solutions}

The methanolic solutions of europium mono and bis terpyridyl and terbium-terpyridyl complexes fluoresce strongly at room temperature and offer possibilities as potential candidates for liquid laser materials.

A $1: 2$ mixture of methanolic solutions of $\mathrm{Eu}^{3^{+}}$and terpyridyl has a fluorescence lifetime $\tau=310 \mu \mathrm{s}$ and $\Phi=0.07$ at room temperature. This $\tau$ value may be compared to $\tau=250 \mu$ s for bis-dipyridyl complex and $\tau=80 \mu$ s for europium-dibenzoylmethide ${ }^{11}$ solution at room temperature. On lowering the temperature, a decrease of quantum efficiency $(\Phi)$ of the $1: 2$ mixture of europium-terpyridyl was noted. This is quite unexpected. Another isolated case where this phenomenon was observed is that of europium acetophenon solu- tion ${ }^{26}$. In solution probably the bis-complex is dissociated to the mono-complex and a free terpyridyl molecule. The energy transfer at low temperature being inferior to that at room temperature may be attributed to collision changes with temperature.

A 1:1 mixture fluoresces slightly when the components are first mixed and the intensity increases with time. Conductometric titration of the $1: 1$ mixture revealed that the complexation in methanol is slow at room temperature, thus supporting the increase in intensity with time of the $1: 1$ mixture. It seems that in methanolic solutions of the mono-terpyridyl complex, the terpyridyl molecule is bound to the europium ion, and the energy transfer from the ligand to the $\mathbf{E u}^{3^{+}}$is an intramolecular one. Addition of excess of $\mathrm{Eu}^{3^{+}}$ions to a solution of the solid complex in methanol quenched the fluorescence of the solution. The same effect is obtained with the addition of $\mathrm{Gd}^{3^{+}}$ions.

\section{Experimental}

The fluorescence spectra were measured with a B e ckman DU spectrophotometer equiped with a fluorescence attachment. Filter no. 22892 (B e c k m a n) was placed between the light source and the sample. Unfortunately the phototube response in the red region and in the yellow of the $\mathrm{Be} \mathrm{ckman}$ instrument is not constant and thus a direct comparison of the ${ }^{5} \mathrm{D}_{0} \rightarrow{ }^{7} \mathrm{~F}_{1}$ and ${ }^{5} \mathrm{D}_{0} \rightarrow{ }^{7} \mathrm{~F}_{2}$ transitions cannot be made. A Schmidt-Haensch "Longo II" spectroscope provided with a wavelength scale was also used to observe the emission spectra.

\section{Adknowledgement}

The author is indebted to Dr. F. Halverson and Dr. J. S. Brinen of the Central Research Laboratory of American Cyanamid for measuring the lifetimes and taking some phosphorescence spectra.

26 E. Matovich and C. K. Suzuki, J. Chem. Phys. 39, 1442 [1963].

Untersuchungen an ternären Fluoriden. IV 1

\section{Kristallstruktur von $\mathrm{CsNiF}_{3}$}

\section{Dietrich Babei}

Laboratorium für Anorganische und Analytische Chemie der Universität Tübingen

(Z. Naturforschg. 20 a, 165-166 [1965] ; eingeg. am 25. Dezember 1964)

Im Verlaufe systematischer Untersuchungen an Fluorperowskiten ${ }^{1}$ wurden die Cäsiumverbindungen $\mathrm{CsNiF}_{3}$ und $\mathrm{CsCuF}_{3}$ dargestellt. Einkristalle von $\mathrm{CsNiF}_{3}$ konn-

1 I. Mitteilung: W. Rüdorff, J. Kändler u. D. Babel, Z. An org. Allg. Chem. 317, 261 [1962]. - II. Mitteilung: W. Rüdorff, G. Lincke u. D. Babel, ibid. 320, 150 [1963] ; III. Mitteilung: D. BABEL, ibid., im Druck.

2 J. J. Lander, Acta Cryst. 4, 148 [1951]. ten aus einer langsam abgekühlten Schmelze von $1 \mathrm{CsHF}_{2}+1 \mathrm{NiF}_{2}$ erhalten werden.

Die Verbindung kristallisiert hexagonal in der Raumgruppe $\mathrm{P}_{3} / \mathrm{mmc}^{-} \mathrm{D}_{6 \mathrm{~h}}^{4}$ mit $a=6,23_{6} \AA, c=5,22_{5} \AA$, $c / a=0,838$ und zwei Formeleinheiten in der Elementarzelle. Mit $\mathrm{Cs}$ in $2 \mathrm{c}, \mathrm{Ni}$ in $2 \mathrm{a}$ und $\mathrm{F}$ in $6 \mathrm{~h}$ ergab sich für $x_{\mathrm{F}}=-0,143_{1}$ ein Zuverlässigkeitswert von $R=0,065$ (45 Reflexe $h k l$ ).

$\mathrm{CsNiF}_{3}$ ist somit ein weiterer Vertreter des $\mathrm{BaNiO}_{3}$. Typs ${ }^{2}$, dem auch $\mathrm{CsNiCl}_{3}{ }^{3}$ angehört. Auf die Verwandtschaft dieser Struktur zum Perowskitgitter ist schon mehrfach hingewiesen worden ${ }^{2-5}$.

${ }^{3}$ G. N. Tishchenko, ref. in Chem. Abstr. 50, 16251 g [1956].

4 B. E. Gushee, L. Katz u. R. Ward, J. Amer. Chem. Soc. 79, 5601 [1957].

5 R. D. Burbank u. H. T. Evans, Acta Cryst. 1, 330 [1948]. 